\title{
Autorregulação e situação problema no jogo: estratégias para ensinar multiplicação
}

\author{
Ana Ruth Starepravo \\ Pontifícia Universidade Católica do Paraná - Curitiba - PR - Brasil \\ Luciane Guimarães Batistella Bianchini \\ Universidade Norte do Paraná- Londrina - PR - Brasil \\ Lino de Macedo \\ Universidade de São Paulo - São Paulo - SP - Brasil \\ Mário Sergio Vasconcelos \\ Universidade Estadual Paulista - Assis - SP - Brasil
}

\section{Resumo}

O conceito de multiplicação na matemática nem sempre é apreendido pelo aluno devido à utilização de práticas pedagógicas convencionais. $\mathrm{A}$ partir desta constatação, partimos da tese de que situações ativas, promotoras de autorregulação por meio da resolução de problemas presentes nos jogos, podem ser uma proposta efetiva na construção de conceitos. Nessa pespectiva nosso objetivo foi analisar as contribuições do Jogo do Resto para a compreensão do conceito de multiplicação. Trata-se de uma pesquisa qualitativa e aplicada que foi realizada em uma sala de aula com 30 alunos do quarto ano do Ensino Fundamental, na qual se utilizou como recurso o Jogo do Resto. Foi possível concluir que o jogo, pelo contexto cognitivo e afetivo que promove, foi cenário deengajamento dos alunos à ação. Os processos de autorregulação e situação problema promovidos nas intervenções envolveram os alunos em condutas de esforço e enfrentamento resultando em apropriação do conceito pretendido. Palavras-chave: Matemática; jogo; autorregulação.

\section{Self-regulation and problem situation in the game: strategies to teach multiplication}

\begin{abstract}
The concept of multiplication in mathematics is not always learned by the student due to the use of conventional pedagogical practices. From this observation, we started from the thesis that active situations, promoting self-regulation through the solution of problems present in the games, it can be an effective proposal in constructing concepts. In this perspective our objective was to analyze the contributions of the Game of the Rest for the understanding of the concept of multiplication. It is a qualitative and applied research that was carried out in a classroom with 30 students of the fourth year of Elementary School, in which the Game of the Rest was used as a resource. It was possible to conclude that the game, through the cognitive and affective context that it promotes, was a scenario of students' engagement with the action. The processes of self-regulation and problem situation promoted in the interventions involved the students in conducts of effort and confrontation resulting in appropriation of the intended concept.
\end{abstract}

Keywords: Mathematics; game; self-regulation.

\section{Autorregulación y situación problema en el juego: estrategias para enseñar la multiplicación}

\section{Resumen}

El concepto de multiplicación en las matemáticas no siempre es aprehendido por el alumno debido a la utilización de prácticas pedagógicas convencionales. A partir de esta constatación, partimos de la tesis de que situaciones activas, promotoras de autorregulación por intermedio de la resolución de problemas presentes en los juegos, pueden ser una propuesta efectiva en la construcción de conceptos. En esa perspectiva nuestro objetivo fue analizar las contribuciones del Juego del Resto para la comprensión del concepto de multiplicación. Se trata de una investigación cualitativa y aplicada que se realizó en una sala de clase con 30 alumnos del cuarto curso de la Enseñanza Primaria, en la cual se utilizó como recurso el Juego del Resto. Fue posible concluir que el juego, por el contexto cognitivo y afectivo que promueve, fue escenario de participación de los alumnos a la acción. Los procesos de autorregulación y situación problema promovidos en las intervenciones abarcaran los alumnos en conductas de esfuerzo y enfrentamiento resultando en apropiación del concepto pretendido.

Palabras clave: Matemáticas; juego; autorregulación. 


\section{Introdução}

O ensino de conceitos matemáticos tem sido um desafio para os professores, dado que muitas práticas consistem em apenas levar o aluno a reproduzir o que lhe foi ensinado. No entanto, no momento de uma aplicação generalizada de um conceito, inúmeras dúvidas são expressas pelo aluno. Isto acontece porque o aluno não construiu conhecimento sobre o tema em questão e, portanto, tal generalização se torna praticamente impossível. Para um sujeito generalizar um conceito, precisará construir esquemas conceituais sobre o tema e isto não implica reproduzir fielmente o que professor disse, mas sim construções e reconstruções ativas do sujeito, decorrentes do processso de autorregulação (Starepravo, 2009; Bianchini \& Vasconcelos, 2014).

A autorregulação compreendida a partir de Piaget e Inhelder (2001) indica a necessária atividade do sujeito a fim de que a aprendizagem ocorra. Os autores definem tal processo como: "uma seqüência de compensações ativas do sujeito em resposta às perturbações exteriores e de regulagens ao mesmo tempo retroativas (sistemas de anéis ou feedbacks) e antecipadoras, que constitui um sistema permanente de tais compensações" (Piaget \& Inhelder, 2001, p. 134).Nessa perspectiva, o indivíduo não elimina o conhecimento anterior, mas o enriquece em sua compreensão, à medida que começa a revê-lo e reconstruí-lo integrando-o a um sistema de relações cada vez mais complexas (Piaget \& Inhelder, 2001).

Entre os conteúdos matemáticos a serem construídos e generalizadospor autorregulação está o conceito da multiplicação. Para Piaget e Szeminska (1975) o conceito de multiplicação tem origem no esquema de correspondência um-para-muitos. O uso de esquemas de correspondência e seu uso em inferências transitivas constituem a base não apenas para construção do número, mas também para a construção de operações aritméticas da adição e da multiplicação. Para os autores, quando as crianças compreendem as correspondências do tipo termo-a-termo (um-para-um) e suas relações transitivas também podem compreender as correspondências do tipo um-para-muitos necessários a construção do conceito de multiplicação.

Para muitos professores, o ensino da multiplicação (bem como das demais operações) visa basicamente o domínio do algoritmo convencional e a sua posterior aplicação para resolver exercícios, priorizando, assim, o domínio dos aspectos sintáticos dessa operação (aqueles relacionados às regras e ao uso de símbolos).

$\mathrm{Na}$ escola, tem sido uma prática corrente iniciar o trabalho relacionado à multiplicação pela apresentação da tabuada aos alunos: primeiro a tabuada do 2 , depois a do 3 , do 4 e, assim por diante, sempre por meio de sua notação simbólica convencional $(2 \times 1=2 ; 2 \times 2=4 ; 2 \times 3=6$, etc. $)$. Nessa perspectiva linear de ensino, na qual a aprendizagem é vista como um encadeamento progressivo de saberes e cuja organização se pauta estritamente na lógica do conteúdo em questão, a tabuada é considerada um pré-requisitopara aprender multiplicação. Como a própria aprendizagem dessa operação aritmética é confundida com o domínio de seu algoritmo convencional, a tabuada acaba se constituindo, muitas vezes, num "passo necessário para aprender a multiplicação", desconsiderando-se que sua compreensão constitui parte do processo de construção desse conceito.

Entretanto, conforme verificou Starepravo (2010), uma criança pode saber a tabuada de cor, e até mesmo usá-la corretamente num algoritmo ensinado pelo professor, sem ter compreendido as relações envolvidas nas operações em questão e, por isso mesmo, não ser capaz de utilizá-la para resolver problemas. A compreensão da multiplicação, conforme indicamos anteriormente, implica um processo de construção desse conceito pela criança, que tem suas origens no esquema de correspondência um-para-muitos e envolve diferentes níveis de abstração, conforme apontado, nos estudos realizados por Piaget e Szeminska (1975), Vergnaud (1983, 1994) e Kamii (2002).

Salientamos, ainda, que na perspectiva dos Campos Conceituais (Vergnaud, 1994), multiplicação e divisão, como operações inversas, são vistas como dois lados da mesma moeda e, portanto, devem ser exploradas, na escola, de forma conjunta e não desvinculada, como acontece numa abordagem linear desses conteúdos.Sendo assim, como possibilitar ao aluno a construção do conceito de multiplicação?

Uma proposta muito útil que tem sido apontada por vários pesquisadores embasados em Piaget (Macedo, Petty, \& Passos, 2000; Fontes, 2004; Kamii, 2002; Villas Bôas, 2007; Starepravo, 2009; Bianchini \& Vasconcelos, 2014), entre outros, é o trabalho com jogos e problematizações. O jogo promove engajamento do sujeito à ação, independentemente de ele saber ou não jogar. $\mathrm{O}$ aspecto afetivo motivador como interesse pelo jogo, seja pela competição, seja até mesmo pelo estar junto com o colega, desloca os alunos de um posicionamento passivo para atuar no jogo com interesse e esforço. Outro ponto importante a destacar no jogo é o seu papel desencadeador do processo de autorregulação por meio das situações problematizadoras que oferecem ferramentas essenciais e necessárias para a construção do conhecimento.

Segundo Freitas (2010), os conceitos matemáticos tornam-se significativos na medida em que são desvendados inicialmente pelos alunos como ferramentas para solucionar problemas. Veiga (2014) e Ott (2004) consideram os problemas como recursos importantes de aprendizagem e, ao contrário do que acontece em geral nas escolas (onde são apresentados após as definições e conceitos, como exercícios de aplicação), devem ser o ponto de partida no ensino dos conteúdos escolares.

Desse modo, foi pensando em uma proposta significativa relacionada ao conceito de multiplicação, que propusemos nossa intervenção por meiode resolução de problemas e jogos. Neste estudo (que faz parte de uma pesquisa maior, na qual trabalhamos com vários tipos de jogos no ensino da matemática), nosso objetivo foi analisar as contribuições do Jogo do Resto ${ }^{1}$ para a compreensão do conceito de multiplicação, bem como refletir acerca da

1 Jogo desenvolvido no laboratório do Programa de Estudos e Pesquisa no Ensino da Matemática (PROEM) da PUC-SP (Franchi, 1995). 
importância das situações problematizadoras e da autorregulação no jogo.

\section{Método}

Nossa pesquisa, caracterizada como qualitativa aplicada, foi desenvolvida numa turma do quarto ano do Ensino Fundamental de uma escola pública de Curitiba, com 30 alunos (entre 8 e 9 anos de idade) e contou com aparticipação da professora da turma. Antes da intervenção, foi realizada uma entrevista com a professora para investigar: o modo como trabalhava a multiplicação e divisão com seus alunos, como percebia o desempenho destes e as expectativas em relação à intervenção proposta. A professora também foi convidada a observar as atividades que iríamos desenvolver, a colaborar quando achasse oportuno e a fazer um relatório de cada aula a partir de um roteiro pré-estabelecido.

$\mathrm{Na}$ intervenção com os alunos utilizamos o Jogo do Resto, um jogo de distribuição, composto pelos seguintes materiais: uma pequena tigela de feijões; seis pratinhos (de plástico ou papelão); um dado; uma tabela de registro individual para cada jogador (Figura 1); um quadro de registro coletivo do total de resto de cada jogador (Figura 2).

O propósito do jogo é, ao final de cinco rodadas, ficar com "um valor de resto" maior que o valor obtido pelos demais jogadores. O número de participante varia de dois a quatro jogadores. Na Figura 3, um exemplo de distribuição possível no jogo.

\section{JOGO DOS RESTOS}

\begin{tabular}{|c|l|l|l|l|}
\hline RODADA & PRATINHOS & $\begin{array}{c}\text { GRÃOS EM CADA } \\
\text { PRATINHO }\end{array}$ & RESTO & TOTAL DE GRÃOS \\
\hline $1^{\mathrm{a}}$ & & & & \\
\hline $2^{\mathrm{a}}$ & & & & \\
\hline $3^{\mathrm{a}}$ & & & & \\
\hline $4^{\mathrm{a}}$ & & & & \\
\hline $5^{\mathrm{a}}$ & & & & \\
\hline
\end{tabular}

Figura 1. Tabela individual para registro das distribuições - Jogo do Resto. Fonte: Elaborado pelos Autores.

\begin{tabular}{|l|l|}
\hline JOGADOR & TOTAL DE RESTO \\
\hline & \\
\hline & \\
\hline & \\
\hline & \\
\hline
\end{tabular}

Figura 2. Quadro para registro do resto total de cada jogador. Fonte: Elaborado pelos Autores.

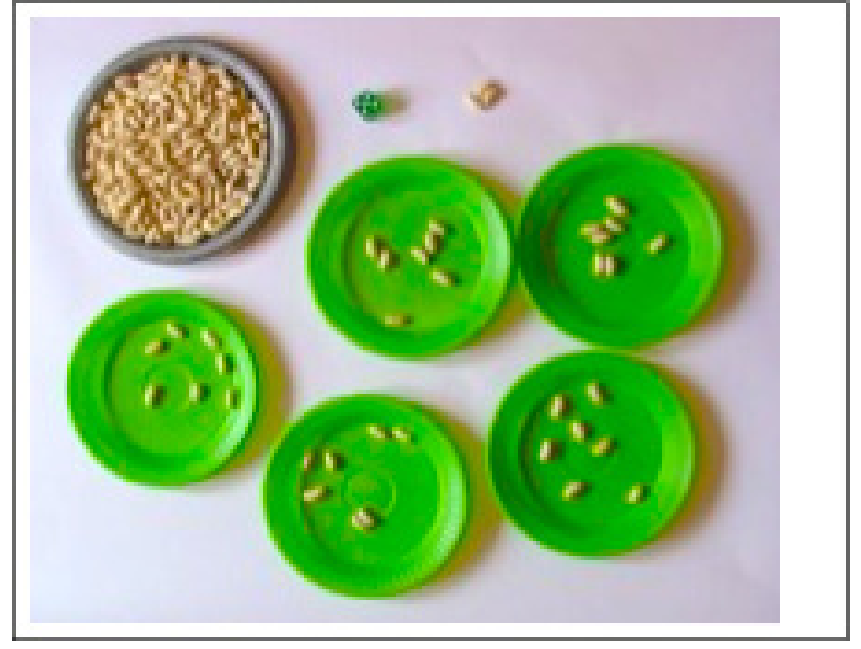

Figura 3. Uma distribuição possível no Jogo do Resto. Fonte: Elaborado pelos Autores.

\section{Modo de jogar}

Antes de iniciar a primeira rodada, cada jogador pega um punhado de feijão da tigela e deixa-o sobre a mesa à sua frente. A seguir o primeiro a jogar lança o dado e o número mostrado no dado indicará a quantidade de pratinhos que ele deve pegar e usar para fazer a distribuição dos feijões do seu punhado. Para a distribuição do punhado de feijões deve seguir as seguintes regras: distribuir o maior número possível de grãos em todos os pratinhos que devem conter a mesma quantidade de grãos.

Ao terminar sua distribuição, o jogador preenche a tabela de registro individual com os dados relativos à jogada efetuada naquela rodada, coloca os feijões novamente na tigela, recolhe os pratinhos usados e passa a vez ao próximo. Todos os outros jogadores, cada um na sua vez, fazem o mesmo. Ao final de cada rodada os jogadores devem devolver os grãos usados e, antes de iniciar uma nova jogada, cada um pega um novo punhado de feijões. O jogo termina quando todos os jogadores tiverem completado as 5 rodadas. Verifica-se o total de resto de cada jogador e registra-se no quadro coletivo. Vence aquele que tiver o maior resto no total.

\section{Procedimento}

Ao todo, foram dedicadas sete aulas ${ }^{2}$ para o trabalho com o Jogo do Resto e a inclusão de situações problemas. $\mathrm{Na}$ aplicação do jogo, os alunos foram divididos em grupos de 4 (podendo jogar no chão ou em uma mesa).

O primeiro dia foi destinado à aprendizagem do jogo pelos alunos. Foram explicadas as regras do jogo e os alunos puderam explorá-lo e tirarem suas dúvidas à medida

2 Chamamos de aula o período em que a pesquisadora atuava em sala de aula por dia, que se estendia das $7 \mathrm{~h} 30$ até as 9h30, ou seja, duas horas. 
que jogavam. Nos outros 6 dias, foram intercalados: um dia jogo livre (para exploração dos alunos) e um dia para resolução de problemas, com objetivo de provocar desafios e que, por autorregulação, eles encontrassem a solução. Após a resolução do problema proposto no jogo, as estratégias utilizadas pelos alunos eram socializadas no grupo a fim de ampliarem possibilidades de ações para as próximas partidas.

\section{Aplicação do jogo em sala de aula}

$\mathrm{Na}$ aula seguinte à apresentação do jogo, com as crianças sentadas no chão, em roda, as regras do jogo foram retomadas a partir da tabela individual preenchida por um aluno na partida realizada na aula anterior. Como esse aluno havia se esquecido de incluir o resto na contagem total dos grãos, tivemos a oportunidade de discutir sobre questões importantes do jogo, tais como: possíveis erros cometidos no preenchimento da tabela; por que o resto não podia ser desconsiderado na determinação da quantidade total de grãos; quais as diferentes formas de realizar as distribuições e de determinar o número total de grãos e ainda se havia alguma forma de garantir a obtenção de um resto de valor mais alto que dos adversários.

É importante ressaltar que ganhar ou perder, nesse jogo, depende da sorte, pois o jogador não pode controlar o número de pratinhos e, consequentemente, o resto. Nas primeiras partidas, percebemos que alguns alunos intuíam que quanto mais feijões tivessem, maior seria o resto, portanto, passavam a pegar uma quantidade grande de grãos em cada rodada. Entretanto, o resto, neste jogo, está mais ligado ao número de pratinhos (divisor), do que à quantidade de grãos (dividendo). No caso de uma distribuição por 6 pratinhos, o jogador poderá ter como resto $0,1,2,3,4$ ou 5 . Mas, se um jogador tiver 2 pratinhos, poderá ter como resto somente 0 ou 1. Assim, quanto maior o número de pratinhos, maior a possibilidade de o resto ser de valor mais alto.

Como adultos, podemos imaginar que a melhor estratégia para realizar a distribuição é contar quantos feijões há no punhado, contar o número de pratinhos, fazer a divisão mentalmente e já colocar o número de grãos que caberá em cada pratinho. As crianças, entretanto, não agem assim. Elas realizam a distribuição sem contar o número total de grãos, colocando-os de um em um, às vezes de dois em dois nos pratinhos, até que não seja mais possível distribuir respeitando a regra de que todos os pratinhos devem ter a mesma quantidade de grãos.

Desta forma, do ponto de vista didático, o objetivo do trabalho com esse jogo é que as crianças sejam capazes de determinar o número total de grãos com base nos dados que foram registrados na tabela individual. Assim, se uma criança usou 5 pratinhos, colocou 7 grãos em cada um e ainda sobraram 3 , ela deve usar esses números para determinar o total de grãos. Pode, por exemplo, fazer $5 \times 7=35$ e $35+3=$ 38 ou ainda $7+7+7+7+7+3=38$. É importante ressaltar, como veremos a seguir, que o uso desses procedimentos não deve ser visto como um pré-requisito para jogar, mas justamente aquilo que as crianças vão aprender a partir da experiência com o jogo e por meio de intervenções realizadas pelo(a) professor(a).

Nossa análise sobre as construções do conceito de multiplicação realizadas pelos alunos nas partidas foi feita a partir de dois eixos: a) dificuldades na realização das distribuições equitativas e o uso da contagem unitária; e b) resolução de problemas e a promoção de processos autorregulatórios no jogo.

\section{Resultados e discussões}

A análise das aulas envolvendo o Jogo do Resto nos permitiu identificar algumas questões importantes sobre os problemas colocados aos alunos pelo jogo e sobre as formas como lidaram com esses problemas. Em primeiro lugar, chamou nossa atenção a dificuldade das crianças em realizar distribuições equitativas na primeira partida. Observamos que vários alunos se perderam na distribuição, deixando seus pratinhos com quantidades desiguais e, por isso, sentiam necessidade de contar os grãos de cada pratinho ao final da distribuição.

Depois de conferir e, se necessário, corrigir a igualdade de grãos entre os pratinhos, usavam novamente a contagem unitária para determinar o número total de grãos. Esse tipo de contagem foi adotado pela maioria dos alunos nas duas primeiras partidas, mesmo por alunos que já haviam usado estratégias de cálculo mental nas atividades exploradas anteriormente, envolvendo arranjo retangular (tanto procedimentos aditivos quanto multiplicativos ${ }^{3}$ ).

É interessante destacar que o uso da multiplicação foi até mesmo sugerido por alguns alunos no momento em que o jogo foi apresentado e que, no decorrer das partidas, a pesquisadora circulava entre os alunos, propondo questões que os levassem a pensar na possibilidade de usar procedimentos aditivos (juntando os pratinhos de dois em dois, por exemplo, recorrendo ao resultado já conhecidos dos alunos envolvendo dobros). Mediante essas intervenções, os alunos usavam corretamente os procedimentos de cálculo, entretanto, voltavam a utilizar a contagem unitária quando a pesquisadora se afastava do grupo. ${ }^{4}$

Por fim, chamamos a atenção para a importância da proposição de problemas sobre o jogo para os progressos da contagem ao cálculo e compreensão do conceito de multiplicação e de divisão, bem como para o uso e compreensão da notação convencional dessas operações.

\footnotetext{
3 Procedimentos aditivos são aqueles em que um produto é obtido pela adição repetida.Por exemplo: para determinar o número total de quadradinhos em um retângulo de $5 \times 6$, os alunos realizavam as adições $6+6+6+6+6$ ou $5+5+5+5+5+5$, operando com unidades simples. No procedimento multiplicativo os alunos operam com uma unidade de ordem superior (5), por exemplo, 5 grupos de 6 (Kami \&Livingston, 1995).

4 Fato observado nas gravações em vídeo (cada aula foi gravada e transcrita nos Diários da Pesquisadora).
} 


\section{Dificuldades para realizar distribuições equitativas}

Em nosso estudo, interpretamos as dificuldades para realizar distribuições equitativas como decorrência da falta de experiência dos alunos com a manipulação de materiais de apoio. Muitas vezes, nas aulas de matemática, os materiais com os quais os alunos trabalham se restringem ao lápis e ao papel, o que acaba por limitar as possibilidades de experimentação e de pesquisa da criança.

Em seus relatórios de observação, a própria professora da turma se declarou surpresa pelo fato de seus alunos não terem percebido que havia pratinhos com quantidades diferentes de feijões, ou seja, o que a surpreendeu foi o fato de apresentarem dificuldades para realizar aquilo que deveria se constituir numa ação corriqueira (pelo menos para crianças dequarto ano).

Conforme mencionado no início deste texto, a ênfase do trabalho com as operações aritméticas na escola recai sobre a manipulação de símbolos. O material de apoio, quando usado, tem como objetivo, a visualização das regras ensinadas e a linguagem notacional convencional (símbolos e sinais matemáticos), as quais, em geral, se constituem no ponto de partida para o trabalho com as operações. Conforme apontado por Kamii (2002), as crianças não aprendem conceitos numéricos pela manipulação de objetos, mas pela abstração reflexiva à medida em que atuam mentalmente sobre os objetos.

Nesse sentido, chamamos a atenção para a importância de se trabalhar com jogos nas aulas de matemática. Entre outros motivos, pelo fato de oferecerem às crianças uma situação significativa para manipular materiais, testar hipóteses e analisar mentalmente os efeitos de sua ação sobre eles.

No decorrer das partidas, mediante a intervenção da pesquisadora, as crianças foram avançando em relação às formas de realizar as distribuições, colocando os grãos de 2 em 2 ou de 3 em 3 nos pratinhos e mantendo um controle maior das distribuições que lhes permitiam realizar correções durante as distribuições. Nas primeiras partidas, se um aluno já tivesse colocado, por exemplo, 4 grãos em cada pratinho, continuasse a distribuição colocando mais 2 grãos em cada pratinho e, antes de completar todos, percebesse que faltariam grãos, retirava todos os grãos de todos os pratinhos e reiniciava a distribuição de um em um. Nas últimas partidas, resolviam um problema como esse tirando apenas os últimos grãos colocados e finalizando a distribuição com um número menor de grãos para cada pratinho, ou seja, melhoraram sua capacidade de realizar julgamentos quantitativos e fazer inferências em situações de distribuição. A situação criada exigiu dos alunos a coordenação de suas ações em relação aos materiais em questão, às regras (limitações impostas pelo meio no qual eles atuavam) e aos outros que jogavam com eles.

\section{Uso da contagem unitária}

Antes mesmo de apresentar o Jogo do Resto, o recurso sistemático à contagem unitária em situações nas quais o raciocínio multiplicativo poderia ter sido aplicado levou-nos a refletir sobre os motivos pelos quais as crianças não usaram espontaneamente a multiplicação, uma vez que receberam instrução formal sobre essa operação no ano anterior.

Conforme mencionamos anteriormente, o processo de ensino dessa noção enfatiza seus aspectos sintáticos (regras e manipulação de símbolos), tratando-a em sala de aula segundo uma perspectiva formalista da matemática. Os alunos, sujeitos desta pesquisa, já conheciam a linguagem matemática relativa à operação de multiplicação e sua inversa, a divisão, e alguns deles foram capazes, até mesmo, de recitar a tabuada. Conforme apontado pela professora da turma, eles também conheciam os algoritmos convencionais da multiplicação e da divisão. Tudo isso, aliado à forma como as crianças lidaram com os primeiros problemas propostos, nos fornece indícios de que o tipo de instrução recebida anteriormente privilegiou o significado formal dos símbolos matemáticos, em detrimento do seu significado referencial, ou seja, daquele que permite ao aluno "associar os símbolos matemáticos às situações reais e torná-los úteis para, entre outras coisas, resolver problemas" (Gómez-Granell, 2008, p. 264).

Em seus relatórios, a professora declarou ter se surpreendido com as dificuldades enfrentadas pelos seus alunos no jogo, tendo registrado o seguinte:

Alguns alunos me surpreenderam pela dificuldade que tiveram em jogar, mesmo após toda a retomada. Eles não perceberam que tinha pratinhos com mais feijões que outros e também não contavam os restos na hora de somar... Surpreendeu-me também o fato de nenhum aluno observar que daria para usar a multiplicação na hora da soma dos feijões.

Segundo a perspectiva construtivista, a aprendizagem de uma noção matemática não se restringe ao domínio de símbolos e regras, mas também envolve a compreensão desse sistema simbólico, constituindo-se, assim, num processo de construção que exige a ação mental do aluno em situações de interação com o objeto de conhecimento em busca da apreensão do seu significado.

Em nossa pesquisa, enquanto as crianças jogavam, a pesquisadora circulava entre as equipes e questionava sobre a possibilidade de contar os grãos de outras formas. Se uma criança tinha 6 pratinhos, cada um contendo 8 grãos, por exemplo, a pesquisadora juntava dois dos pratinhos e perguntava se elas não eram capazes de calcular "de cabeça" a quantidade total (sabendo que cada pratinho tinha 8). A resposta era imediata (16). Em seguida, a pesquisadora juntava outros dois pratinhos e perguntava se era necessário realizar algum cálculo para saber quantos grãos havia ali. As crianças percebiam logo se tratar da mesma quantidade (16). Assim, percebiam que podiam recorrer ao cálculo mental e ao seu conhecimento dos dobros para contar os grãos juntando os pratinhos de dois em dois (assim, 6 pratinhos com oito grãos cada, podiam ser contados como $16+16+16$ ).

Apesar de verificarmos a progressiva substituição, por parte das crianças, dos procedimentos de contagem unitária 
por procedimentos de cálculo (adição e multiplicação), chamou nossa atenção o fato de que, diante de problemas novos, envolvendo os mesmos tipos de situações multiplicativas, mas em contextos diferenciados, as crianças voltavam a utilizar a contagem unitária (como ocorreu no Jogo do Resto, em relação às atividades envolvendo arranjo retangular ${ }^{5}$ ).

Esses resultados suscitaram duas questões importantes sobre as quais consideramos importante refletir. A primeira refere-se à concepção de aprendizagem como um processo que ocorre a longo prazo e que está sujeito a avanços e retrocessos. A segunda diz respeito à visão que o adulto (professor) tem em relação aos procedimentos de cálculo como uma forma mais fácil ou mais rápida de resolver problemas que também podem ser resolvidos pela contagem.

Sobre a primeira questão, salientamos que um conhecimento construído pela criança em um dado contexto não é imediatamente transferível a outros, porque está fortemente vinculado à situação que Ihe deu origem. Assim, para compreender a noção de multiplicação, é importante que a criança tenha oportunidade de trabalhar com seus diferentes significados, mas também com um mesmo tipo de situação multiplicativa em contextos variados. Quando a criança descobre que um procedimento usado em determinado contexto pode também ser eficaz quando aplicado a outro diferente, ela começa a "descolar" os conhecimentos de situações mais específicas e estes passam a ser progressivamente generalizados ou "re-descontextualizados", conforme expressão usada por Brousseau (2008).

A segunda questão diz respeito à visão que o adulto (professor) tem em relação aos procedimentos de cálculo mental, considerados como uma forma mais fácil ou mais rápida de resolver problemas, que também podem ser resolvidos pela contagem. $\mathrm{O}$ fato de as crianças terem recorrido sistematicamente à contagem unitária, mesmo reconhecendo a possibilidade de se usar procedimentos aditivos ou multiplicativos, mostra que o recurso à primeira estratégia não implica necessariamente a incompreensão da multiplicação. Para um adulto que tem fluência no cálculo, de fato torna-se mais fácil usar a adição ou a multiplicação para determinar, por exemplo, o número total de quadradinhos em um retângulo ou de grãos em um determinado número de pratinhos, mas para a criança pode não ser. Isso foi indicado por um dos alunos quando afirmou que era mais rápido contar de um em um os feijões nos pratinhos do que usar procedimentos aditivos ou multiplicativos, como haviam feito dois de seus colegas.

Nesse sentido,o cálculo mental pode facilitar ou agilizar a solução de um problema para o qual a contagem unitária se mostra um procedimento eficaz, somente na medida em que a criança começa a ter fluência nele. Antes disso, utilizá-lo significa trocar um procedimento sobre o qual a criança tem domínio, que o executa bem, por outro que ela ainda não domina e que, portanto, ainda não é o mais fácil para ela. A interpretação que fazemos do regresso

5 Situações associadas à configuração retangular (linhas e colunas). Problemas desse tipo envolvem também relações de correspondência um-para-muitos, porém na perspectiva de bidimensionalidade. às estratégias de contagem por parte dos alunos em nossa pesquisa encontra apoio no Institut National de Recherche Pédagogique (1995):

É preciso aceitar também que, para situações aparentemente análogas, determinado aluno dá a impressão de regredir: para ele a situação mais segura nem sempre é a mais econômica e a aprendizagem também é feita de hesitações, de retornos aparentes... antes de as aquisições se estabilizarem (p. 120).

A fluênciana utilização de procedimentos como o cálculo mental é adquirida pelo seu uso repetido em situações variadas. Falamos aqui em repetição, em exercício, porém não se trata de uma repetição enfadonha, sem sentido, mas em situações significativas para as crianças, como é o caso da repetição que ocorre, por exemplo, no contexto de um jogo. Kamii (2002) ressalta que, do ponto de vista da aritmética, os jogos podem constituir um excelente contexto para o treino das quatro operações, justamente pela satisfação que proporcionam e pelo retorno imediato que oferecem às crianças, que não precisam esperar por uma validação do professor, mas do próprio jogo ou dos colegas.

No Jogo do Resto, os grãos estavam sempre disponíveis para a realização da contagem unitária. Assim, se pretendíamos que as crianças usassem o cálculo, e não o fizessem apenas porque a pesquisadora assim o desejava, era necessário explorar situações nas quais elas não dispusessem desses objetos de contagem. Fizemos isso por meio da proposição de problemas através do jogo.

\section{Contribuições da resolução de problemas e da promoção de processos autorregulatórios no jogo}

Consideramos que a resolução de problemas sobre o jogo contribuiu de modo efetivo para os avanços dos alunos, tanto no que se refere à aquisição da fluência no cálculo, quanto no domínio progressivo da linguagem matemática formal da multiplicação. Além disso, foram também importantes para conquistas na esfera social, ou seja, para além do conteúdo escolar.

O jogo criou um contexto rico para a proposição de problemas por meio dos quais os alunos puderam analisar a utilização dos procedimentos de cálculo, bem como de suas respectivas representações notacionais convencionais (linguagem matemática formal).

Em vários episódios registrados durante os momentos em que as crianças resolviam problemas sobre o jogo foi possível observar a contribuição deste tipo de atividade. Como exemplo, destacamos aqui um trecho de um desses episódios, referente a um problema no qual as crianças deveriam observar dois registros produzidos por um aluno numa mesma rodada de uma partida do Jogo do Resto, a fim de fazer um julgamento sobre a validade destes registros, sendo que somente um deles estava correto (Figura 4). 
1. Veja os registros feitos pelo Pedro na $4^{\mathrm{a}}$ rodada do JOGO DOS RESTOS:

\begin{tabular}{|c|c|c|c|c|}
\hline RODADA & PRATINHOS & $\begin{array}{c}\text { GRÄOS EM CADA } \\
\text { PRATINHO }\end{array}$ & RESTO & TOTAL DE GRÃOS \\
\hline $4^{\circ}$ & 5 & 3 & 4 & 12 \\
\hline
\end{tabular}

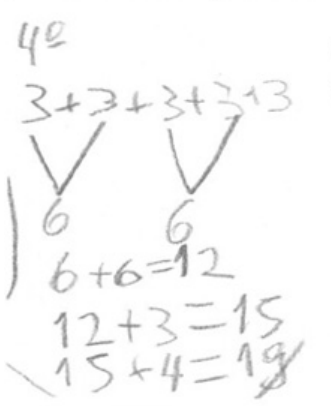

a. Qual o total de grãos registrado pelo Pedro na tabela de pontuação?

b. Qual o total de grãos registrado pelo Pedro no cálculo mostrado ao lado?

c. Um dos resultados registrados por ele está errado. Qual deles está errado? Por que?

Figura 4. Problema elaborado com base no Jogo do Resto. Fonte: Elaborado pelos Autores.

Naquela partida, combinamos que após a realização da distribuição em cada rodada o jogador registraria em sua tabela individual o número de pratinhos, de grãos em cada pratinho e o resto. Teria, então, que devolver os feijões à tigela (ou seja, desfazer a distribuição realizada) antes de determinar o número total de grãos. Assim, ele já passava a vez para o próximo jogador, enquanto usava os dados que registrou na tabela para determinar o número total de grãos. Sugerimos que usassem o verso da folha da tabela para registrar os cálculos realizados em cada rodada 6 .

Usamos os registros produzidos por um aluno na quarta rodada (na tabela e no verso da folha), para elaborar o problema, que foi proposto para a turma toda. No primeiro registro (4a), que havia sido feito na tabela do jogo, havia um erro no número que indicava o total de grãos (12). O segundo registro (4b), feito no verso dessa tabela, e que deveria ter sido usado como referência para determinar o número total de grãos, tratava-se de um procedimento aditivo, cujo resultado (19) foi obtido pela adição repetida do número de grãos de cada pratinho $(3+3+3+3+3)$ sucedida pelo acréscimo do resto (4). O trecho apresentado a seguir mostra como o próprio aluno que produziu os registros (identificado como $\mathrm{PEDRO}^{7}$ ) se expressa enquanto procura descobrir qual dos registros está incorreto:

(PEDRO olha para o registro feito na tabela) três grãozinhos em cada... eu tinha cinco pratinhos (olha para a colega que está ao seu lado) três... ó... (olha para a tabela, levanta um dedo, olha para a colega) seis... (levanta outro dedo, olha para frente) três... seis... nove (levanta mais um dedo, olha para a colega). Doze... (levanta o quarto dedo) quinze (levanta o quinto dedo). Quinze... tá (aponta a tabela) em

6 Nossa intenção era a de colocar as crianças diante do problema de determinar o número total de grãos sem o acesso aos objetos de contagem.

7 O nome utilizado é fictício. todos os pratinhos juntos têm quinze grãos. (Diário da Pesquisadora).

Sua fala e seus gestos mostram que ele operou simultaneamente com unidades de ordens superiores (5 unidades de 3) e com unidades inferiores (3). Nos dedos ele marca cada unidade simples (número de pratinhos), fazendo a correspondência entre três unidades de um e uma unidade de 3 e verbaliza as unidades de ordem superior, já numa relação de inclusão que leva em conta essa correspondência (três, seis, nove...). Esse tipo de procedimento revela uma construção essencial à compreensão da multiplicação, conforme apontado por Kamii (2002). Problemas como estes são significativos para os alunos porque fazem referência a situações vivenciadas por eles, despertando, assim, seu interesse em buscar uma solução que lhes satisfaça, que lhes faça sentido.

Salientamos, ainda, a importância da análise e discussão sobre os procedimentos mobilizados pelos alunos para resolver os problemas propostos. Quando os alunos são incentivados a elaborar procedimentos pessoais para resolver problemas e a discutir entre si sobre a validade desses procedimentos, tornam-se mais independentes e confiantes em sua capacidade de aprender matemática. Os resultados de nosso estudo indicaram mudanças de atitudes dos alunos no envolvimento com as atividades propostas, na relação com a matemática, na forma de tratar os problemas apresentados, no tratamento dispensado ao erro e na capacidade de comunicação e expressão.

Mais de uma vez a professora da classe mencionou, em seus relatórios, estar se surpreendendo com o bom desempenho de alguns alunos que considerava "fracos em matemática". Numa conversa que tivemos antes do início da intervenção, ela já havia mencionado especificamente uma aluna (identificada em nosso estudo como SAB) por apresentar muita dificuldade em matemática. Contou até 
que ela não participava das aulas dessa disciplina junto com seus colegas, mas era encaminhada para outra sala, na qual outra professora realizava uma intervenção individual com ela, num programa de "recuperação paralela".

Convém destacar que durante nossa inserção em sala, SAB teve uma participação muito expressiva. Sempre tentou resolver os problemas propostos oferecendo-se, várias vezes, para ir ao quadro mostrar a solução apresentada. Nessas ocasiões, observamos bastante desenvoltura para explicar seus registros. Um exemplo pode ser visto no trecho transcrito a seguir, no qual ela explica como procedeu para resolver um problema proposto com base no Jogo do Resto (Figura 5), cujo enunciado era o seguinte: Na segunda rodada, Lohayne distribuiu 15 feijões em 3 pratinhos e ficou com 5 grãos em cada um. Se ela distribuísse esses mesmos feijões em cinco pratinhos, quantos grãos colocaria em cada um?
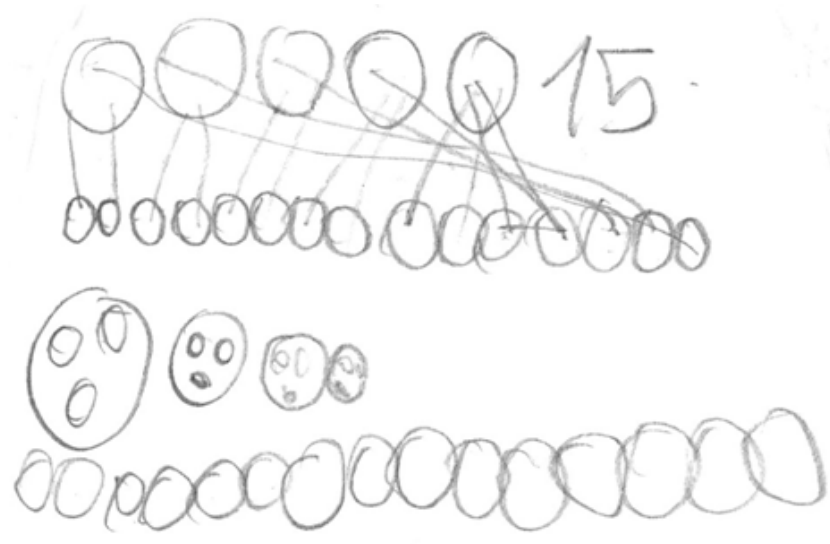

Figura 5. Solução apresentada por SAB a um problema envolvendo o Jogo do Resto. Fonte: Elaborado pelos Autores.

Destacamos a seguir mais uma cena compartilhada no grupo para resolverem o problema. SAB diz:

eu desenhei os cinco pratinhos e depois os quinze feijões... [aponta no desenho - Figura 5] daí eu fui fazendo essas linhas aqui pra mostrar os feijões que podiam colocar em cada pratinho... esses dois aqui, depois esses dois aqui... esses dois... esses dois e esses dois [enquanto fala aponta cada dupla de feijões e os respectivos pratinhos aos quais foram ligados]. Daí... depois... sobraram esses aqui... [aponta os cinco últimos feijões] daí então eu fui colocando em cada pratinho... em um em um. ${ }^{8} \mathrm{Na}$

8 Como pode ser observado nos registros, depois de distribuir os 10 primeiros grãos (dois a dois), ela tentou colocar mais dois em cada pratinho (fez os traços ligando o $11^{\circ}$ e o $12^{\circ}$ grãos ao último pratinho). Como viu que sobraram 3 grãos e que não seria possível colocar mais dois em cada pratinho, contou os feijões que haviam sobrado após a primeira distribuição (5) e verificou que poderia colocar mais um grão em cada pratinho. Quando fez o registro no quadro, já fez direto um traço ligando cada um dos cinco últimos grãos a um pratinho. sequencia PEDRO faz uma pergunta: $E$ por que você fez aqueles desenhos lá embaixo... explica pra gente, $S A B$ [apontou o desenho dos pratinhos com os feijões dentro]. SAB responde: ah... estes daqui é porque daí ficou muito riscado aqui... [aponta os primeiros registros] daí então eu fiz aqui pra mostrar melhor como que ficou... esses todos aqui... [aponta os 15 feijões enfileirados] dentro dos pratinhos. PEDRO: $E$ quanto que deu... em cada pratinho? SAB: Em cada? É... [olha para o desenho] deu três em cada. (Diário da Pesquisadora).

Constatamos, em nosso estudo, que a resolução de problemas, tanto daqueles oriundos de uma partida em si, quanto daqueles propostos oralmente ou por escrito depois das partidas, contribuiu não apenas para a compreensão dos conceitos matemáticos envolvidos, mas também para o desenvolvimento de uma atitude investigativa por parte dos alunos. Verificamos, assim, mudanças na qualidade da relação das crianças com a matemática: envolvimento nas atividades propostas, elaboração de procedimentos pessoais para resolver problemas, participação nas discussões realizadas. Segundo a professora da turma, "perderam o medo de errar" e "pegaram mania de querer explicar como realizavam as atividades".

\section{Considerações Finais}

A nossa investigação partiu do pressuposto de que as situações de desequilíbrio e autorregulação no processo de construção do conhecimento, como o de multiplicação na matemática, são de fundamental importância para práticas pedagógicas, nas quais o conhecimento é concebido como uma construção ativa do aluno. Além disso, é preciso considerar que tais processos são desencadeados, especialmente, em situações que possibilitam significado ao aluno.

É igualmente importante que, numa etapa posterior, tal conhecimento possa ser generalizado, que possa ser desvinculado da situação na qual foi gerado para se aplicar a novas situações. Para esse processo de redescontextualização, o aluno deve se tornar consciente dos mecanismos usados para obtenção de uma resposta, tanto daqueles que o conduziram a uma resposta correta, ou seja ao sucesso, quanto daqueles que resultaram em fracasso. Usar um mesmo conhecimento em diferentes contextos pode ajudar o aluno a perceber invariantes, aquilo que permanece enquanto forma quando se modifica um conteúdo. O ensino deve visar à superação da relação de oposição entre repetição e conscientização, tratando-os numa perspectiva de complementaridade, conforme a concepção piagetiana acerca do fazer e do compreender (Piaget, 1978).

É nesse sentido que o professor pode encontrar no jogo um recurso de grande auxílio para a realização de sua tarefa de ensinar matemática, uma vez que ele conjuga desafios novos a cada partida. As crianças assim podem se divertir jogando, envolvidas naquilo que Brousseau (2008) denomina como uma situação a-didática, enquanto o professor 
trabalha observando como seus alunos jogam. Essa é uma excelente oportunidade para observar, por exemplo, como organizam suas ações e se são capazes de avaliar os seus resultados, quais conhecimentos mobilizam e a que tipo de estratégias recorrem. Valendo-se dessas informações, o professor pode planejar suas intervenções, escolher problemas que mobilizem os conhecimentos que os alunos já possuem, mas que os façam melhorá-los, ampliá-los, aperfeiçoá-los. Assim, o jogo, não deve ser escolhido ao acaso, mas fazer parte de um projeto de ensino do professor, com a intencionalidade de pariticipar, de fato, do processo de construção do conhecimento pelo aluno.

\section{Referências}

Bianchini, L.G.B. \& Vasconcelos, M.S. (2014.). Significação e sentimentos dos alunos quando erram na matemática. Psicologia da Educação, 38, 63-71.

Brousseau, G. (2008). Introdução ao estudo das situações Didáticas: conteúdos e métodos de ensino. São Paulo: Ática.

Fontes, A.E.H.G.T. (2004). Os níveis de compreensão interpessoal no contexto do jogo simbólico.Tese de Doutorado, Universidade Estadual de Campinas, Campinas, SP.

Franchi, A. (1995). Compreensão das situações multiplicativas elementares. Tese de Doutorado, Pontifícia Universidade Católica de São Paulo, São Paulo, SP.

Freitas, J.L.M. (2010). Situações didáticas. Em S.D.A. Machado \& cols. (Orgs), Educação matemática: uma introdução (Série Trilhas, pp. 65-87). São Paulo: EDUC.

Gómez-Granell, C. (2008). A aquisição da linguagem matemática: símbolo e significado. Em A. Teberosky \& L. Tolchinsky (Orgs.), Além da alfabetização: a aprendizagem fonológica, ortográfica, textual e matemática (4ª ed., pp. 257-282). São Paulo: Ática.

Institut National de Recherche Pédagogique. (1995). À descoberta dos números: contar, cantar e calcular (M.F. Pinto, Trad., Coleção Perspectivas Actuais/Educação). Porto: Asa.
Kamii, C. (2002). A criança e o número (27ª ed.). Campinas: Papirus.

Kamii, C. \& Livingston, S.J. (1995). Desvendando a aritmética: implicações da teoria de Piaget ( $3^{\mathrm{a}}$ ed.). Campinas: Papirus.

Macedo, L., Petty, A.L.S., \& Passos, N.C. (2000). Aprender com jogos e situações-problema. Porto Alegre: Artmed.

Ott, M.B. (2004). Ensino por meio de solução de problemas. Em V.M. Candau (Org.), A didática em questão (23a ed.). Petrópolis: Vozes.

Piaget, J. (1978). Fazer e compreender. São Paulo: Melhoramentos/ EDUSP.

Piaget, J. \& Szeminska, A. (1975). A gênese do número na criança (2ª ed.). Rio de Janeiro: Zahar; Brasília: INL.

Piaget, J. \& Inhelder, B. (2001). Psicologia da criança (17 ed.). Rio de Janeiro: Bertrand; Brasil.

Starepravo, A.R. (2010). A multiplicação na Escola Fundamental 1: análise de uma proposta de ensino. Tese de Doutorado, Universidade de São Paulo, São Paulo, SP.

Starepravo, A.R. (2009). Jogando com a matemática: números e operações. Curitiba: Aymará.

Veiga, I.P.A. (2014). Novas tramas para as técnicas de ensino e estudo. Campinas: Papirus.

Vergnaud, G. (1994). L'enfant, la mathématique, et la réalité: problèmes de l'enseigment des mathématiques à l'école élémentaire ( $5^{\mathrm{a}} \mathrm{ed}$.). Paris: Peter Lang.

Vergnaud, G. (1983). Multiplicative Structures. Em R. Resh \& M. Landau (Orgs.), Acquisition of mathematics concepts and processes (pp. 127-74). New York: Academic Press.

Vilas Bôas, M.C. (2007). Construção da noção de número na educação infantil: jogos como recurso metodológico. Dissertação de Mestrado, Universidade de São Paulo, São Paulo, SP. 


\section{Apêndice A - Problemas elaborados com base no Jogo do Resto}

2. Este é o registro feito pelo Gabriel França na $3^{a}$ rodada do JOGO DOS RESTOS. Confira se ele calculou corretamente o total de grãos e mostre como você fez para calcular.

\begin{tabular}{|c|c|c|c|c|}
\hline RODADA & PRATINHOS & $\begin{array}{c}\text { GRÃOS EM CADA } \\
\text { PRATINHO }\end{array}$ & RESTO & TOTAL DE GRÃOS \\
\hline $3^{a}$ & 6 & 3 & 1 & 18 \\
\hline
\end{tabular}

3. Veja o registro de cálculo feito pela Carolina na $3^{a}$ rodada do JOGO DOS RESTOS e responda as perguntas:

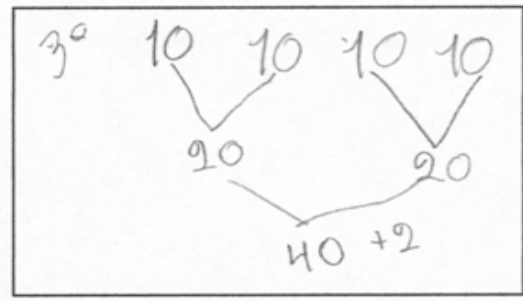

a. Quantos pratinhos ela usou?

b. Quantos grãos colocou em cada pratinho?

c. Sobrou resto? Explique como você descobriu.

d. Quantos grãos de feijão ela tinha ao todo?

4. Veja o registro de cálculo feito pela Letícia para calcular o total de feijões na 5 a rodada do Jogo dos Restos. Mostre com um desenho a distribuição dos feijões nos pratinhos feita pela Letícia nesta rodada e depois preencha a tabela.

\begin{tabular}{l|l|l|l|l|}
5 a $4 \times 3=12$ & 12 \\
$+\quad 3$ & 5 \\
\hline RODADA & PRATINHOS & $\begin{array}{c}\text { GRÃOS EM CADA } \\
\text { PRATINHO }\end{array}$ & RESTO & TOTAL DE GRÃOS \\
\hline $5 a$ & & & & \\
\hline
\end{tabular}

5. A Lohainy usou a adição para calcular o total de feijões em cada rodada. Ela poderia calcular de outra forma? Como? Mostre outra forma de calcular o feijōes da Lohainy em cada rodada.
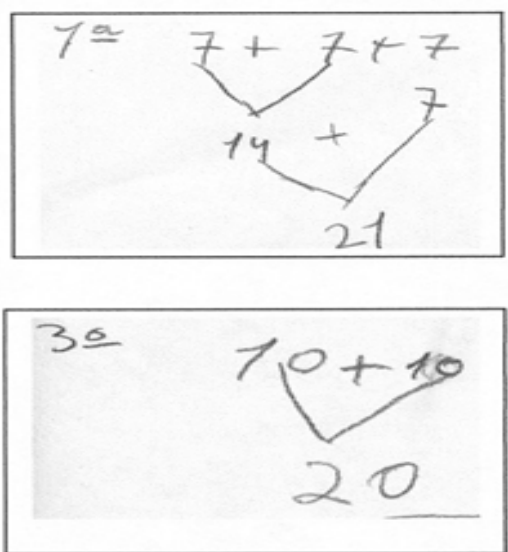
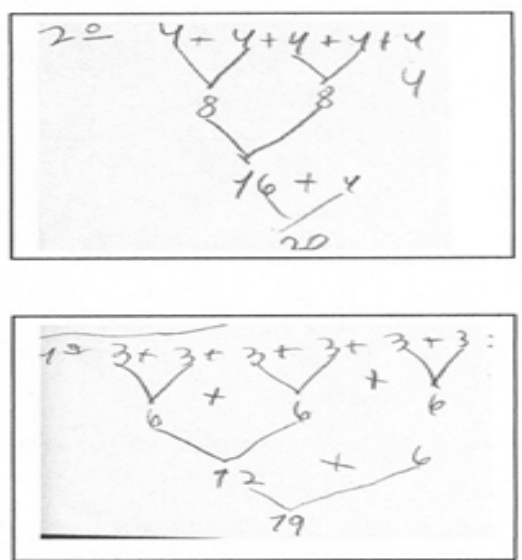
Recebido em: 30/10/2015

Reformulado em: 12/09/2016

Aprovado em: 19/09/2016

Sobre os autores

Ana Ruth Starepravo (starepravo@uol.com.br)

Doutora em Educação. Pontifícia Universidade Católica do Paraná (PUC-PR)

Luciane Guimarães Batistella Bianchini (luannbi@hotmail.com)

Doutora em Psicologia. Programa de Pós-graduação em Metodologias para o Ensino de Linguagens e suas Tecnologias da Universidade Norte do Paraná (UNOPAR)

Lino de Macedo (limacedo@me.com)

Doutor em Psicologia. Universidade de São Paulo (USP)

Mário Sergio Vasconcelos (vascon@assis.unesp.br)

Doutor em Psicologia. Programa de Pós-graduação em Psicologia da Universidade Estadual Paulista (UNESP)

Multiplicação, autorregulação e jogo * Ana Ruth Starepravo, Luciane Guimarães Batistella Bianchini, Lino de Macedo \& Mário Sergio Vasconcelos 